\title{
A Partnership Among Local Public Health Agencies, Elementary Schools, and a University to Address Childhood Obesity: A Scalable Model of the Assess, Identify, Make it Happen Process
}

\section{Benjamin C Ingman ( $\sim$ benjamin.ingman@du.edu )}

University of Denver Morgridge College of Education https://orcid.org/0000-0003-0830-8926

\section{Carla J Loecke}

University of Denver Morgridge College of Education

\section{Elaine S Belansky}

University of Denver Morgridge College of Education

\section{Research}

Keywords: Implementation science, research intermediaries, elementary schools, school health, rural, public health agencies

Posted Date: October 11th, 2021

DOl: https://doi.org/10.21203/rs.3.rs-951439/v1

License: (c) (1) This work is licensed under a Creative Commons Attribution 4.0 International License.

Read Full License 


\section{Abstract}

BACKGROUND: One pathway to addressing childhood obesity is through implementing evidence-based practices (EBPs) shown to promote nutrition and physical activity in K-12 school settings. AIM (Assess, Identify, Make it happen) is a strategic planning process to engage stakeholders in implementing EBPs in their K-12 schools. Local Public Health Agencies (LPHAs) are a potential partner to facilitate this process to a broader audience of rural school communities.

METHODS: A process and outcome evaluation design was applied in this study to examine the extent to which LPHAs effectively implemented AIM with rural/frontier schools in comparison to university staff. Data collection included a post-meeting surveys completed by facilitators, a post-intervention interview with facilitators, a survey of school task force members at the end of the AIM process, and systematic documentation of the intervention.

\section{RESULTS:}

Reach. Among the 26 eligible elementary schools, 18 (69.2\%) agreed to participate.

Effect. In total, schools facilitated by LPHAs fully implemented an average of 4.0 changes per school, while schools facilitated by the university staff fully implemented an average of 3.7 changes.

Adoption. Among the five LPHAs in the target region, all five agreed to partner on the initiative, but some agencies were unable to identify sufficient personnel to facilitate all schools in their catchment area.

\section{Implementation.}

- In total, 89 of 94 (94.68\%) meetings scheduled by LPHA facilitators occurred. 47 of 48 (97.92\%) meetings scheduled by the university staff occurred.

- The university staff self-reported $93 \%$ of agenda items in the AIM process as "completely" followed while LPHA facilitators reported $41 \%$ of agenda items as "completely" followed.

- Task force satisfaction with the AIM process and facilitator showed limited variance across LPHAs and university-facilitated schools.

Maintenance. Of the 16 school districts that agreed to participate in the school-based version of AIM, 9 (56.25\%) also participated in a district-wide version of AIM two years later.

CONCLUSION: AIM is an effective process for implementing EBPs in elementary schools when facilitated by LPHAs. Effective partnerships, a nuanced approach to fidelity, scalability considerations, and the role of technical assistance and training all contributed to the successful implementation of this LPHAElementary school partnership.

\section{Contributions To The Literature}


- AIM (Assess, Identify, Make it happen) is an effective process for implementing evidence-based practices in elementary schools when facilitated by Local Public Health Agencies.

- A nuanced approach to program fidelity, in which facilitators adapted the intervention based on the local context, was identified as a contributing factor to success of the initiative.

- Factors that contributed to the successful partnership with Local Public Health Agencies as community-based research intermediaries include: 1) revise the intervention to honor new facilitators/implementers, 2) adapt to the local capacity of the research intermediary, and 3) adopt a comprehensive approach to training and technical assistance.

\section{Background}

\section{Childhood obesity, schools, and the role of research intermediaries.}

Childhood obesity rates have continued to climb over the last several decades across the country, with higher rates of obesity among rural youth (Probst et al., 2018), Latinx youth (Flórez et al., 2019), and youth living in poverty (Drewnowski, 2012). Schools are situated to address these systemic inequities by promoting nutrition and physical activity (Story et al., 2009). This is especially the case in rural communities, where schools are often considered the hubs of social and cultural activities (Roberts, 2017).

While there are many effective practices known to increase student opportunities for physical activity and nutrition in schools (Brennan et al., 2014), many rural schools have not implemented those practices or recommendations. For example, recess before lunch was shown to increase students' consumption of healthy foods in 1996 (Getlinger et al., 1996); yet 15 years later, only $46 \%$ of rural Colorado schools were offering recess before lunch (Author et al., 2013).

Research intermediaries, or organizations that help community-based entities learn about and implement evidence-based practices (among other functions) (Franks \& Bory, 2017), have made progress in facilitating the connection between research and practice in K-12 schools (Courtney, 2020). However, additional strategies are necessary to reach all schools, especially in rural, high-poverty settings.

One pathway to address these gaps in research to practice is through engaging school stakeholders in a process to implement evidence-based practices in their schools. Such a process can reach more schools if additional organizations and agencies are identified and mobilized as research intermediaries.

\section{AIM (Assess. Identify. Make it Happen).}

AIM (Assess, Identify, Make it Happen) is a strategic planning process to promote healthy nutrition and physical activity in K-12 schools. In this process, a task force of community stakeholders convenes to 
Assess the current status of evidence-based practices (EBPs) shown to promote healthy nutrition and physical activity, Identify_EBPs to put in place, and Make it happen by implementing those EBPs. The 12month process is facilitated by a trained and certified facilitator.

AIM was tested in rural, elementary schools using a pair-randomized control trial and demonstrated to be an effective implementation strategy for disseminating effective school-based environment, policy, and practice features previously shown to increase students' physical activity and healthy nutrition (Author et al., 2013). AIM schools made an average of 4.4 evidence-based changes per school with $90 \%$ still in place a year later compared to schools that used the CDC's School Health Index which made an average of 0.6 effective changes with $66 \%$ in place a year later. This first study demonstrated that AIM is an effective method of promoting the implementation of EBPs when facilitated by university staff working directly with rural communities. While these results bode well for the process itself, relying on university staff to implement AIM poses a challenge to scalability. A delivery model in which individuals from rural communities facilitate the process in their own communities would greatly improve the scalability of AIM.

\section{Local Public Health Agencies.}

Local Public Health Agencies (LPHAs) were identified as entities well positioned to promote the scalability of AIM. Among the ten essential services of LPHAs are to: (3) Communicate effectively to inform and educate people about health, factors that influence it, and how to improve it; (4) Strengthen, support, and mobilize communities and partnerships to improve health; (5) Create, champion, and implement policies, plans, and laws that impact health (CDC, 2021). These functions closely align with the purposes of the AIM process. Additionally, LPHAs are physically proximate to target populations, have considerable knowledge of the community, and prioritize addressing childhood obesity. Although LPHAs in rural regions may face challenges such as lack of qualified staff, and limited access to training, information, and resources (Rosenblatt et al., 2002; Turner et al., 2008), they are also well positioned to leverage local cultural assets and flexible structures for developing new productive partnerships and networks (Century et al., 2003). Further, half of the 2,400 Local Health Departments/Agencies in the USA serve rural populations (Leider et al., 2020). This confluence of factors positions LPHAs as a promising pathway to scalability for school- and community-based initiatives. Others have been successful in partnering with LPHAs to implement school-based initiatives (Cottrell et al., 2017), although concrete assessments of implementation characteristics in applying such an approach are scant in the literature.

Partnering with LPHAs to facilitate the AIM process required important changes to several elements of the AIM process, facilitator training, and technical assistance (Milat et al., 2013). Specifically, this change in implementation model was coupled with the development of an AIM website, the revision of AIM meeting guides and materials, streamlining and automating labor-intensive aspects of the process (e.g., creating an automated survey and report generating system). For these reasons, an implementation science framework was adopted to evaluate not only the outcomes of the intervention, but also to 
describe key dimensions of implementation across the RE-AIM framework (Glasgow et al., 1999). This work contributes to discourse of implementation science that seeks to understand the effectiveness of interventions when implemented in real-world settings and provides additional perspectives on the factors that influence successful implementation (e.g., Damschroder et al., 2015).

\section{Purpose of the study.}

The purpose of this study was to examine the extent to which LPHAs could effectively facilitate AIM with rural/frontier schools in comparison to university staff. The RE-AIM framework was used for this inquiry because it provides a systematic and comprehensive structure to evaluate interventions as implemented in complex, real-world settings.

\section{Methods}

\section{Program implementation}

\section{Program description: AlM process.}

The goal of the AIM process (Assess, Identify, Make it happen) is to implement evidence-based practices (EBPs) for promoting student nutrition and physical activity in school settings. For each school participating in AIM, a task force of community stakeholders (including the school principal, classroom teachers, physical education teachers, school staff, food service directors, nurses, parents) convenes for a series of meetings led by a facilitator trained and certified in the process. The AIM facilitator is provided a 'facilitator guide' which includes detailed agendas, activities, and talking points for each meeting in the process, as well as actions and tasks to complete between the meetings. Before the AIM process begins, baseline data is collected via a three-module survey based on the School Environment and Policy Survey (SEPS) (Author et al., 2013). This survey is completed by the principal, food service director, and physical education teacher and generates a Best Practice Report that provides the status (fully implemented, partially implemented, not implemented) of EBPs for nutrition and physical activity.

After the task force has been recruited and oriented to the process, they discuss strengths and challenges related to student health behaviors and school practices to promote student health. The task force also reviews the Best Practice Report to understand the current implementation status of nutrition and physical activity EBPs in the school and generate a list of potential changes to make to the school. This list of potential changes is later revised and clarified before final selections are made based on the importance of a change for student health and the feasibility of implementing it.

The task force engages in several action planning activities to promote the successful implementation of the selected changes. This includes planning to get approval and buy-in for changes; planning for sustainability; and creating a task-oriented timeline for implementing changes and assigning tasks. The 
task force convenes for a final meeting to review progress in implementation, and plan any next steps for the group, such as checking in on implementation or transitioning to a wellness team.

The AIM process was implemented with two separate cohorts and revised between cohorts 1 (8 schools) and 2 (10 schools) based on feedback from facilitators and task force members. The most significant revision was the amount of time dedicated to AIM meetings and activities; the number of meetings was reduced from 9 to 7 meetings, and the length of meetings was reduced from 120 to $60-75$ minutes (see Table 1: AlM Process Meeting Descriptions).

\section{Program setting.}

This study took place from 2014-2016 in a rural/frontier plains region in Colorado encompassing 7 counties and 15,962 square miles (larger than the state of Maryland) that includes the lowest county health rankings and highest childhood poverty rates in the state (Robert Wood Johnson Foundation, 2020).

\section{Program recruitment.}

Project staff recruited LPHAs and schools through in-person visits at each site during the academic school year preceding the intervention. School recruitment meetings were typically attended by the school principal and physical education teacher. Schools received $\$ 4,000$ to complete the AIM process. LPHA recruitment meetings were attended by agency directors and staff identified as potential AIM facilitators, who were in most cases nurses. Informational flyers explaining the AIM process and Memorandums of Understanding were key artifacts used during recruitment efforts. LPHAs were remunerated at $10 \%$ FTE of the individual(s) facilitating schools for each school facilitated through the AIM process (e.g., one school facilitated through AIM by a LPHA employee earning $\$ 50,000$ resulted in a $\$ 5,000$ payment to the LPHA).

LPHAs also participated in a readiness assessment interview during the recruitment phase, which provided an opportunity to discuss their motivations and reservations to participating. LPHAs noted the shared priority of addressing obesity (all 5 included obesity in their most recent Health Assessment Plans) and the potential benefits of closely collaborating with schools in their service area.

\section{Training and technical assistance for LPHAs.}

LPHA directors designated staff to facilitate the AIM process. LPHA staff were trained through a five-day training in August and a one-day booster training midway through the school year. Two facilitators who worked with both cohort 1 and cohort 2 attended a one-day training focused on revisions from the previous year in lieu of attending the five-day training a second time. Ongoing support to discuss progress and answer questions consisted of monthly conference calls among facilitators and university staff, and individualized ad hoc technical assistance (see Meyers et al., 2012). 


\section{Process and outcome evaluation design}

This study used a process and outcome evaluation approach to monitor and evaluate the implementation of the AIM process (Handley et al., 2016). Process evaluation efforts, which were guided by the RE-AIM framework (Glasgow et al., 1999), began with the recruitment of LPHAs and schools and ended 6 months after all participating schools had completed the AIM process. Outcome evaluation was focused on the implementation of evidence-based practices in participating schools and general satisfaction with the AIM process and facilitators. This study was approved by the Colorado Multiple Institution Review Board.

\section{Data collection}

\section{Post-meeting surveys (AIM facilitators).}

All AIM facilitators (LPHA staff and university staff) completed a post-meeting survey at the end of each AIM meeting. These surveys included attention to logistical aspects of the meeting (date, time, and length of the meeting); facilitator preparation; fidelity to the meeting guide; task force dynamics (member participation and tension during the meeting); and feedback about the meeting agenda and process. There was an average of 33 items per post-meeting survey. Implementation status of changes was included in the final AIM meeting survey.

\section{Post-intervention interviews (AIM facilitators).}

All AIM facilitators participated in a semi-structured interview at the end of the intervention. These interviews were held in person at the health agency office or in a community setting and focused on LPHA facilitator perspectives on four topics: 1) facilitation of the AIM process at the school, 2) partnership with the university team, 3) impacts on the agency or its personnel, and 4) suggested improvements to the AIM process.

\section{Post-process survey (AIM task force members).}

Those participating in the AIM process and serving on the AIM task force completed a 53-item survey at the end of the AIM process. Key topics included in this survey were perceptions of the facilitator and overall satisfaction with the AIM process.

\section{Process documentation.}


Other data, correspondence, meeting notes, and artifacts that document the process were collected throughout the intervention to inform and contextualize dimensions of the intervention as guided by the RE-AIM framework.

\section{Data analysis}

Evidence-based practices were coded as nutrition or physical activity by the task forces proposing the changes. These practices were then coded to the sub-areas of changes by two researchers. Discrepancies in coding were identified and discussed by raters to determine the final coding.

Interviews with LPHAs were transcribed and analyzed using structural, open, and axial coding. (Glaser \& Strauss, 2009; Tolley et al., 2016). Two researchers completed the analysis, with regular meetings to identify inconsistencies and discrepancies in coding and to discuss emergent themes (Houston et al., 2010). Project documents and records were analyzed by researchers to ensure the accurate and complete depiction of the intervention as it unfolded.

\section{Results}

\section{Reach}

The target region for recruitment included 26 elementary schools. These schools served 4,323 students (48.2\% Hispanic, 65.7\% Free/reduced lunch). Among these schools, 18 (69.2\%) agreed to participate and LPHA staff facilitated 12. A local individual was hired as university staff to facilitate the remaining 6 schools (see Figure 1. Demographics of participating and non-participating elementary schools). Schools that participated in the intervention as facilitated by LPHAs had a slightly higher Hispanic population (49.2\%) and slightly lower free and reduced lunch rate (63.9\%) than the target population (see Figure 2: Scatterplot of student Free/Reduced Lunch rate and \% Hispanic for participating and non-participating schools).

\section{Effect}

The AIM process is designed to expedite the implementation of evidence-based practices that promote nutrition and physical activity for students at participating schools. The implementation status of identified practices was documented at the final meeting of the AIM process using the following options: fully implemented, partially implemented, planned for implementation, and not implemented.

LPHA cohort 1 had an average of 5.20 changes implemented per school; LPHA cohort 2 had an average of 3.29 changes per school. The university-facilitated schools had an average of 3.67 changes fully implemented per school in both cohorts 1 and 2. In total, schools facilitated by LPHAs saw an average of 4.00 changes fully implemented per school, while schools facilitated by university staff had an average 
of 3.67 changes fully implemented per school. The results of the type of changes implemented are further delineated in Figure 3: Number and implementation status of EBPs.

\section{Adoption}

We attempted to recruit 5 LPHAs for partnership, and successfully recruited $100 \%$ of these LPHAs. In total, these 5 LPHAs serviced a population of 71,162 across 7 counties. While all 5 LPHAs agreed to partner and implement AIM, two agencies were unable to identify personnel to facilitate all schools in their catchment area. Namely, one agency was able to facilitate just 1 of the 6 schools in their region, and another agency was able to facilitate 1 of the 2 schools in their region. Both LPHAs cited lack of available qualified personnel as the primary factor that limited their capacity to facilitate AIM in all schools in their regions. Among the 18 schools successfully recruited for participation in the process, the 5 LPHAs were able to facilitate $12(66.67 \%)$ of those schools.

\section{Implementation}

\section{Number and length of meetings.}

In total, 94 meetings were scheduled with the 12 schools facilitated by LPHAs. Among these, 89 (94.68\%) meetings took place. The 6 schools facilitated by university staff were scheduled for a total of 48 meetings, and 47 (97.92\%) took place.

Meeting lengths varied between cohorts 1 and 2 due to revisions made to the meeting guide based on feedback from cohort 1 . There was no difference in mode for the meeting length between LPHA and university facilitators for either cohort (Cohort 1 mode $=$ 1:46-2:00 hours; Cohort 2 mode $=$ 1:01-1:15 hours). There was, however, a tendency for the university facilitator meetings to run longer than the LPHA facilitators across both cohorts. This was most pronounced during cohort 2 where the university facilitator meetings skewed longer (right) and the LPHA facilitator meetings skewed shorter (left) (see Figure 4: Length of meetings for cohorts 1 and 2).

\section{Time spent preparing; feeling prepared.}

Facilitators indicated how much time they spent preparing for each meeting. The university facilitator reported spending more than 60 minutes preparing for $77 \%$ of meetings while LPHA facilitators reported spending more than 60 minutes preparing for $50 \%$ of meetings (see Figure 5.1). Relatedly, the university facilitator strongly agreed with the statement "I felt very prepared to facilitate this meeting" for $94 \%$ of meetings while the LPHA facilitators strongly agreed with that statement for $39 \%$ of meetings (see Figure $5.2)$. 


\section{Fidelity to facilitator guide.}

AIM facilitators rated how closely they followed the facilitator guide for each agenda item of each meeting using the following scale: Not at all (0-24\%, did not do this part of the meeting); Some (addressed $25-49 \%$ of the items); Mostly (addressed $50-74 \%$ of the items); Completely (addressed 75$100 \%$ of the items). The university facilitator reported $93 \%$ of agenda items as "completely" while LPHA facilitators reported $41 \%$ of agenda items as "completely" (See Figure 5.3).

\section{Idea sharing and tension during AIM meetings.}

Facilitators also rated the extent to which they agreed or disagreed with two statements: "Most task force members shared their ideas during the meeting"; and "There was tension among some of the task force members during the meeting". The university facilitator strongly agreed that most task force members shared their ideas during the meeting $94 \%$ of the time, while the LPHA facilitators strongly agreed with this statement $44 \%$ of the time (see Figure 5.4). The university facilitator also strongly disagreed with the statement of tension among task force members $98 \%$ of the time, while LPHA facilitators strongly disagreed with this statement $79 \%$ of the time (see Figure 5.5).

\section{Taskforce satisfaction with the process and facilitators.}

At the end of the AlM process, task force members were invited to participate in a task force survey which included items focused on their satisfaction and interpretations of the AIM process (Figure 6.1) and facilitator (Figures 6.2, 6.3). These results show limited difference between satisfaction with the facilitator, although the LPHA-facilitated schools show slightly higher overall satisfaction with the process.

\section{Maintenance}

The AIM process and partnerships with LPHAs resulted in several new connections and enduring practices amongst schools and LPHAs. At the close of the initiative, we offered an AIM do-it-yourself training and disseminated manuals for applying AIM without the support of a university facilitator. We did not systematically evaluate the uptake of such an approach at schools, however. Other outcomes from the initiative include school districts successfully segueing AIM task forces into functional wellness teams, and LPHA staff continuing to meet with school district personnel to support them in their wellness efforts. Post-intervention interviews with LPHA staff also expressed optimism on the long-term outcomes for LPHA-school partnerships resulting from this initiative.

Relatedly, a subsequent iteration of AIM was offered 2 years after this initiative was completed in the same region. This version of AIM was altered in focus (from nutrition and physical activity to all 
components of the Whole School, Whole Community, Whole Child model) (Lewallen et al., 2015), scope (from school to district level), and implementation model (from nine, 60-75 minute meetings, to three, 6 hour meetings facilitated by University staff). Of the 16 school districts that agreed to participate in the initial version of AIM discussed in this study, 9 (56.25\%) also participated in this subsequent, extended version of AIM. Further, of the 6 districts that declined to participate in the initial version of AIM, 4 (66.67\%) agreed to participate in the subsequent extended version of AIM.

\section{Discussion}

Implementing the AIM process in partnership with LPHAs allowed for a more scalable model of the AIM process to be implemented across a large, rural/frontier geographic region with outcomes comparable to previous iterations of AIM. This study raises a few points of ongoing consideration for those engaged in implementing interventions in partnership with local organizations as research intermediaries.

\section{Comparisons between university and LPHA facilitators of AlM.}

This study demonstrates that LPHAs succeeded in facilitating schools through the AIM process and that schools were successful in implementing EBPs. This positions AIM as a promising model for broader implementation to make schools in rural communities healthier places for students. There were, however, differences between LPHAs and university facilitators in their facilitation of AIM in this initiative. The LPHA-facilitated schools averaged lower marks than the university facilitator on 1) fidelity to the process; 2) the percentage of meetings that took place versus those that were planned; and 3) the length and completion rate of meetings. Meetings facilitated by LPHAs also reported greater tension and lower incidence of all task force members sharing their opinions during the meetings when compared to meetings guided by the university facilitator. These differences are at odds with the outcome measures, which showed an average of slightly more evidence-based practices implemented with LPHAs (4.00 EBPs per school) than with the university facilitator (3.67 EBPs per school).

\section{Considerations of fidelity.}

While fidelity is typically positioned as a key determinant to maintaining desirable outcomes of interventions, this study revealed that higher fidelity to the process as prescribed was not associated with an increased prevalence of desired outcomes (Lewis et al., 2019). From a training and technical assistance perspective, our approach to fidelity was aligned with suggestions that an adaptive approach to fidelity is essential when scaling up programming (Pérez et al., 2016). In this initiative, facilitators were encouraged to waver from the facilitator guide when they considered it in the best interest of the process and task force. In some instances, facilitators were also supported in making more significant alterations to the process while retaining critical activities of AIM. Anecdotal evidence from this initiative supports 
this approach to process fidelity. For example, there were instances in this implementation of AIM in which the high fidelity to the process demonstrated by facilitators was viewed as inflexibility and a detriment to quality by task force members. Conversely, approaching the AIM process with flexibility to the needs and contexts of LPHA and school partners was also viewed as critical to ensuring the success of the initiative. These findings inspire a continued consideration of fidelity in the context of health-based interventions in partnership with community organizations in school settings.

\section{Importance of effective partnerships, scalability considerations, training, technical assistance.}

This study also emphasizes the benefits of adopting a flexible and supportive approach to partnering with community-based research intermediaries. In retrospect, we view approaches to 1) adapting to local capacity, 2) scalability, and 3) training and technical assistance, as worthy of emphasis.

\section{Adapting to local capacity.}

Adapting the intervention plan based on the capacity of LPHAs was critical to ensuring success and promoting the greatest reach possible. For instance, although it was not the intended implementation model, we hired a community affiliate to operate as facilitator to account for the lack of available personnel in two LPHAs. Flexibility in implementation with this agency allowed us to still reach the target audience of schools in this region despite a lack of capacity at the LPHA.

\section{Scalability.}

The effort to create a scalable model was executed with consideration of key dimensions of scalability (see Milat et al., 2013). Revisions to the process that better positioned it for success in this scalable model include developing a new training and support model, revamping materials (meeting guide, website, supportive materials), amending the method of implementation (meeting evaluations, school surveys to generate automated reports), and, perhaps most importantly, reducing the amount of time required to complete the process. In the context of rural LPHAs and schools, it is important that initiatives that add to the existing workload honor the time constraints and responsibilities of existing partners and take efforts to promote the greatest efficiency possible.

\section{Training and technical assistance.}

Finally, many LPHA staff reported that the training and technical assistance they received throughout this intervention was both critical in aiding their successful facilitation and dissimilar to much of the training and support they had received in the past. This reifies the importance of training and technical assistance 
to position a model for successful scalability. In this case, a training and TA approach that draws on various theories of education, training, and professional development was found to develop the necessary knowledge and skills in facilitators.

\section{Conclusion}

Implementing AIM with rural LPHAs as facilitators was an effective method of implementing evidencebased practices for physical activity and nutrition in rural elementary schools. The results outlined above support the continued exploration of partnerships with LPHAs as research intermediaries and the promise of further applications of AIM as a catalyst of expediting the research to practice delay.

Future studies may further engage in the question of fidelity in implementation science. Namely, the findings of this study support the importance of discourse that interrogates the notion of fidelity to interventions alongside authenticity to the context and locality in which an intervention is implemented (Lewis et al., 2019). Other research may address how partnerships with LPHAs can be leveraged and best structured to address areas of need in rural contexts (e.g., professional development needs, lack of funding, resources, or personnel) and promote positive outcomes to address a compendium of health behaviors and conditions.

\section{Abbreviations}

AIM Assess, Identify, Make it Happen

LPHA Local Public Health Agency

EBP Evidence-Based Practice

\section{Declarations}

- This study was approved by the Colorado Multiple Institution Review Board (COMIRB).

- The datasets generated during and analyzed during the current study are not publicly available due to considerations of confidentiality, but may be made available from the corresponding author on reasonable request and in compliance with COMIRB.

- The authors declare that they have no competing interests.

- This study was supported with funding from the Colorado Health Foundation.

- We wish to acknowledge partnering Local Public Health Agencies, partnering elementary schools, and [identifying information redacted].

\section{References}

1. Author. (2013). 
2. Brennan LK, Brownson RC, Orleans CT. Childhood Obesity Policy Research and Practice: Evidence for Policy and Environmental Strategies. Am J Prev Med. 2014;46(1):e1-16. https://doi.org/10.1016/j.amepre.2013.08.022.

3. CDC - 10 Essential Public Health Services-CSTLTS. (2021, March 18). https://www.cdc.gov/publichealthgateway/publichealthservices/essentialhealthservices.html.

4. Century I of M. (US) C. on E. P. H. P. for the 21 st, Gebbie, K., Rosenstock, L., \& Hernandez, L. M. (2003). Public Health Agencies: Their Roles in Educating Public Health Professionals. In Who Will Keep the Public Healthy? Educating Public Health Professionals for the 21st Century. National Academies Press (US). https://www.ncbi.nIm.nih.gov/books/NBK221185/.

5. Cottrell L, Northrup K, Wittberg R. Challenges and Lessons Learned From a Prevention Research Center Partnership. Am J Prev Med. 2017;52(3):255-7. https://doi.org/10.1016/j.amepre.2016.08.016.

6. Courtney MB. The Education Agency as Research Intermediary. Journal of Educational Issues. 2020;6(1):1. https://doi.org/10.5296/jei.v6i1.16174.

7. Damschroder L, Hall C, Gillon L, Reardon C, Kelley C, Sparks J, Lowery J. (2015). The consolidated framework for implementation research (cfir): Progress to date, tools and resources, and plans for the future. Implementation Science, 10(S1), A12,

1748-5908-10-S1-A12

. https://doi.org/10.1186/1748-5908-10-S1-A12.

8. Drewnowski A. The Economics of Food Choice Behavior: Why Poverty and Obesity Are Linked. Obesity Treatment Prevention: New Directions. 2012;73:95-112. https://doi.org/10.1159/000341303.

9. Flórez KR, Katic BJ, López-Cevallos DF, Murillo R, Cancel-Tirado D, Aponte-Soto L, Echeverria SE. The double burden of food insecurity and obesity among Latino youth: Understanding the role of generational status. Pediatric Obesity. 2019;14(9):e12525. https://doi.org/10.1111/ijpo.12525.

10. Franks RP, Bory CT. Strategies for Developing Intermediary Organizations: Considerations for Practice. Families in Society. 2017;98(1):27-34. https://doi.org/10.1606/1044-3894.2017.6.

11. Getlinger MJ, Laughlin VT, Bell E, Akre C, Arjmandi BH. Food waste is reduced when elementaryschool children have recess before lunch. J Am Diet Assoc. 1996;96(9):906-8. https://doi.org/10.1016/s0002-8223(96)00245-3.

12. Glaser BG, Strauss AL. (2009). The discovery of grounded theory: Strategies for qualitative research (4. paperback printing). Aldine.

13. Glasgow RE, Vogt TM, Boles SM. Evaluating the public health impact of health promotion interventions: The RE-AIM framework. Am J Public Health. 1999;89(9):1322-7. https://doi.org/10.2105/AJPH.89.9.1322.

14. Handley MA, Gorukanti A, Cattamanchi A. Strategies for implementing implementation science: A methodological overview. Emerg Med J. 2016;33(9):660-4. https://doi.org/10.1136/emermed-2015205461. 
15. Houston SD, Hyndman J, McLean J, Jamal A. (2010). The Methods and Meanings of Collaborative Team Research. https://doi.org/10.1177/1077800409346411.

16. Leider JP, Meit M, McCullough JM, Resnick B, Dekker D, Alfonso YN, Bishai D. The State of Rural Public Health: Enduring Needs in a New Decade. Am J Public Health. 2020;110(9):1283-90. https://doi.org/10.2105/AJPH.2020.305728.

17. Lewallen TC, Hunt H, Potts-Datema W, Zaza S, Giles W. The Whole School, Whole Community, Whole Child model: A new approach for improving educational attainment and healthy development for students. The Journal of School Health. 2015;85(11):729-39. https://doi.org/10.1111/josh.12310.

18. Lewis CC, Lyon AR, McBain SA, Landes SJ. Testing and Exploring the Limits of Traditional Notions of Fidelity and Adaptation in Implementation of Preventive Interventions. J Primary Prevent. 2019;40(1):137-41. https://doi.org/10.1007/s10935-019-00539-2.

19. Milat AJ, King L, Bauman AE, Redman S. The concept of scalability: Increasing the scale and potential adoption of health promotion interventions into policy and practice. Health Promotion International. 2013;28(3):285-98. https://doi.org/10.1093/heapro/dar097.

20. Pérez D, Van der Stuyft P, Zabala MdelC, Castro M, Lefèvre P. A modified theoretical framework to assess implementation fidelity of adaptive public health interventions. Implementation Science. 2016;11(1):91. https://doi.org/10.1186/s13012-016-0457-8.

21. Probst JC, Barker JC, Enders A, Gardiner P. Current State of Child Health in Rural America: How Context Shapes Children's Health. The Journal of Rural Health. 2018;34(S1):s3-s12. https://doi.org/10.1111/jrh.12222.

22. Robert Wood Johnson Foundation. County health rankings. County Health Rankings \& Roadmaps; 2020. https://www.countyhealthrankings.org/reports/state-reports.

23. Roberts P. (2017). Rural schools as hubs for the socio-educational development of communities. 27 , 5.

24. Rosenblatt RA, Casey S, Richardson M. Rural-urban differences in the public health workforce: Local health departments in 3 rural western states. American Journal of Public Health; Washington. 2002;92(7):1102-5.

25. Story M, Nanney MS, Schwartz MB. Schools and Obesity Prevention: Creating School Environments and Policies to Promote Healthy Eating and Physical Activity. The Milbank Quarterly. 2009;87(1):71100. https://doi.org/10.1111/j.1468-0009.2009.00548.x.

26. Tolley EE, Ulin PR, Mack N, Robinson ET, Succop SM. (2016). Qualitative methods in public health: $A$ field guide for applied research (Second edition). Wiley.

27. Turner AM, Stavri Z, Revere D, Altamore R. From the ground up: Information needs of nurses in a rural public health department in Oregon. Journal of the Medical Library Association. 2008;96(4):335-42. https://doi.org/10.3163/1536-5050.96.4.008.

\section{Table}


Due to technical limitations, table 1 is only available as a download in the Supplemental Files section.

\section{Figures}

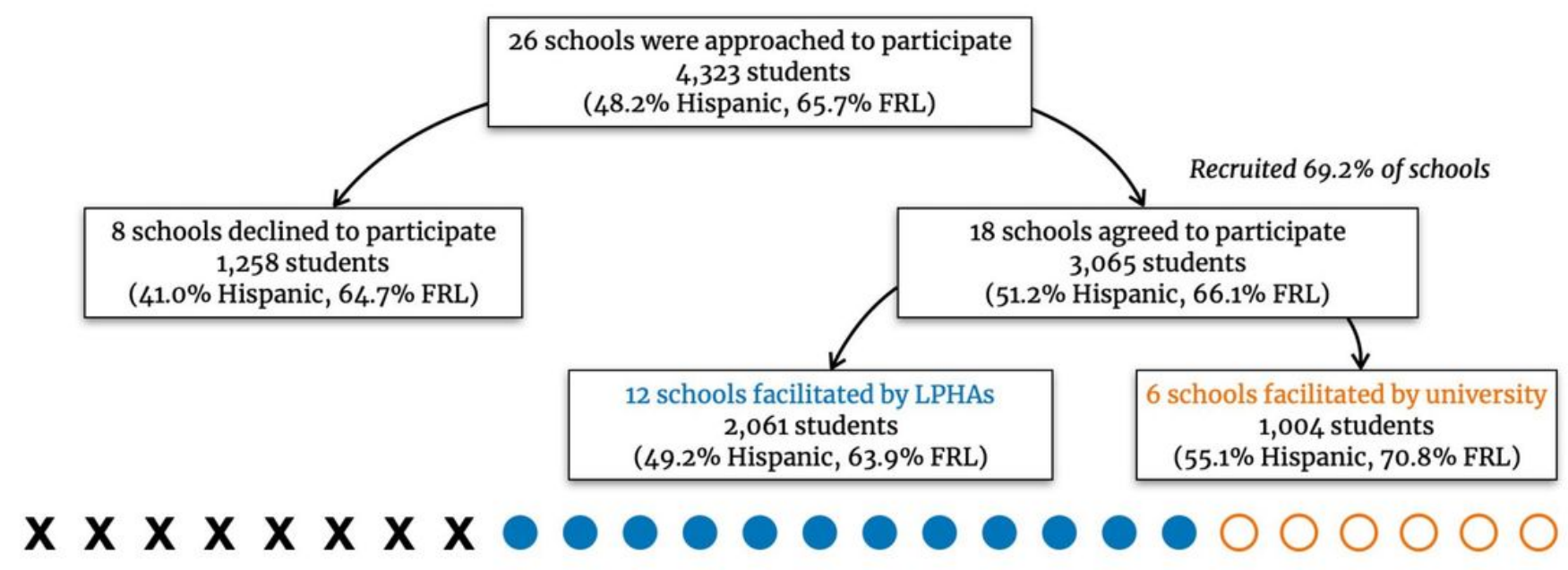

\section{Figure 1}

Demographics of participating and non-participating elementary schools 
- Schools facilitated by LPHA

- Schools facilitated by university

$\times$ Schools that did not participate

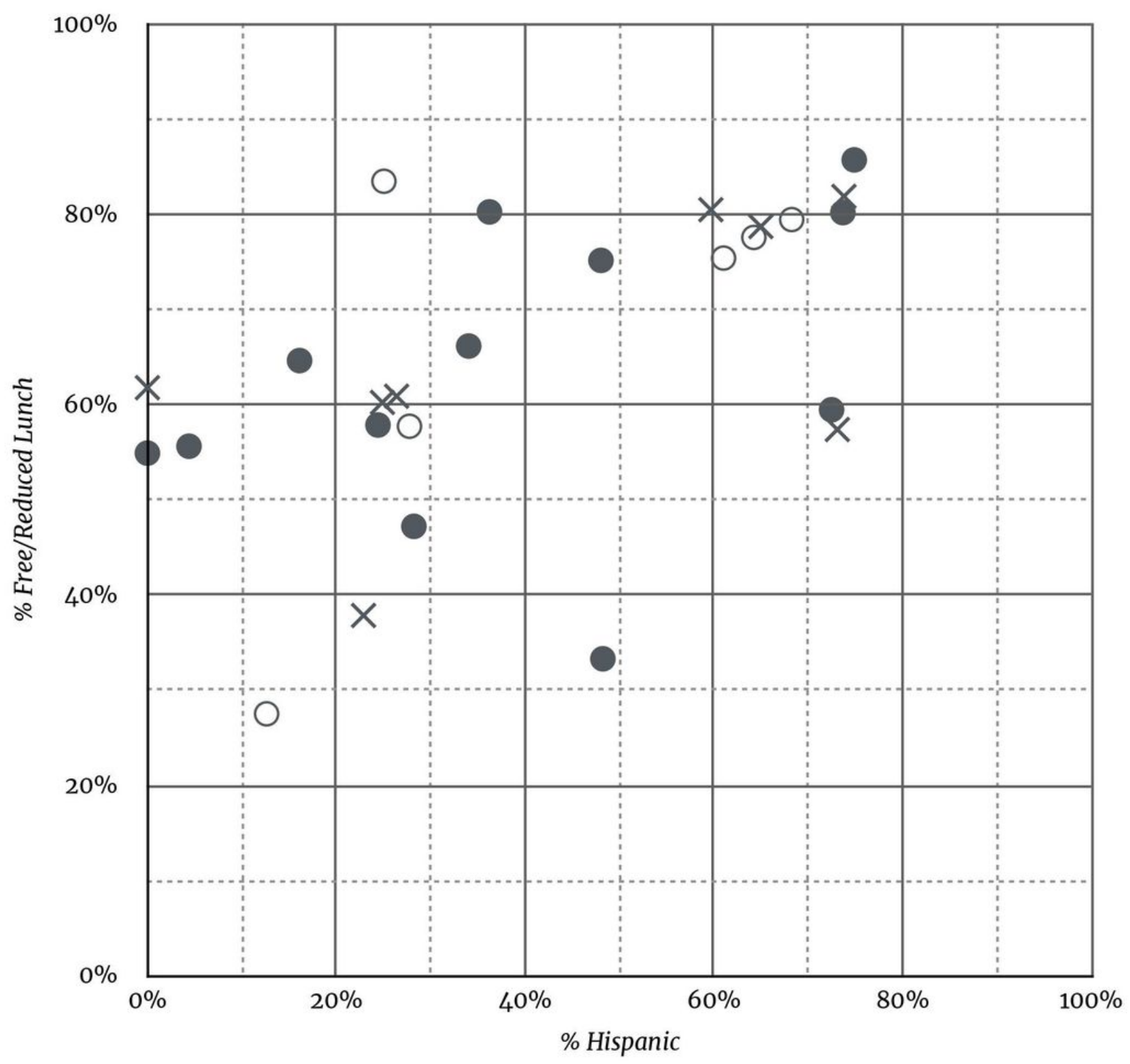

Figure 2

Scatterplot of student Free/Reduced Lunch rate and \% Hispanic for participating and non-participating schools. 
Fully Implemented

Partially implemented

Planned

Not Implemented

LPHA Facilitated Schools (12 schools)

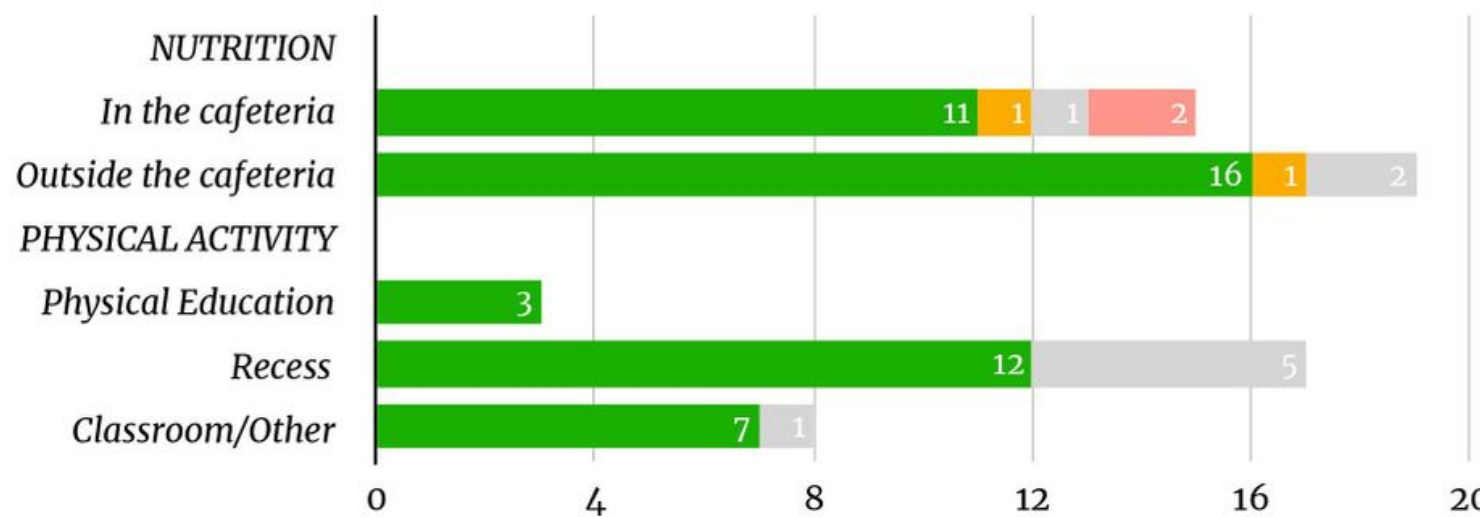

Number of Evidence-Based Practices

University Facilitated Schools (6 schools)

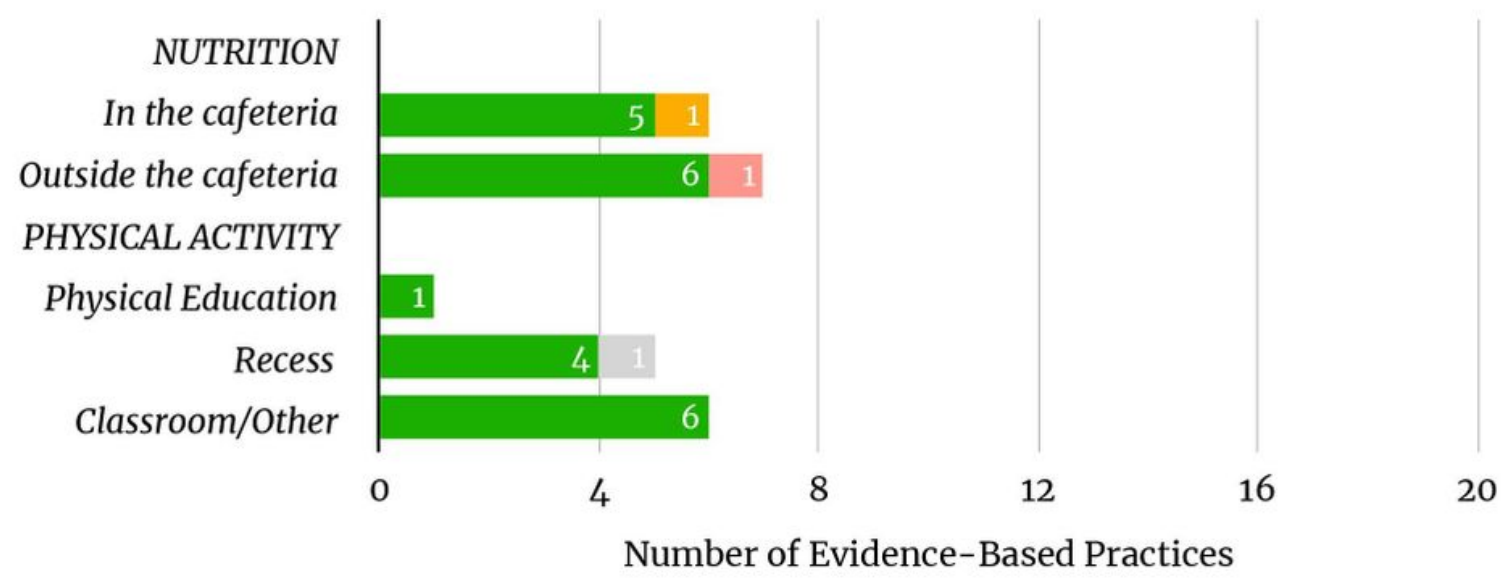

\section{Figure 3}

Number and implementation status of EBPs 


\section{Cohort 1}

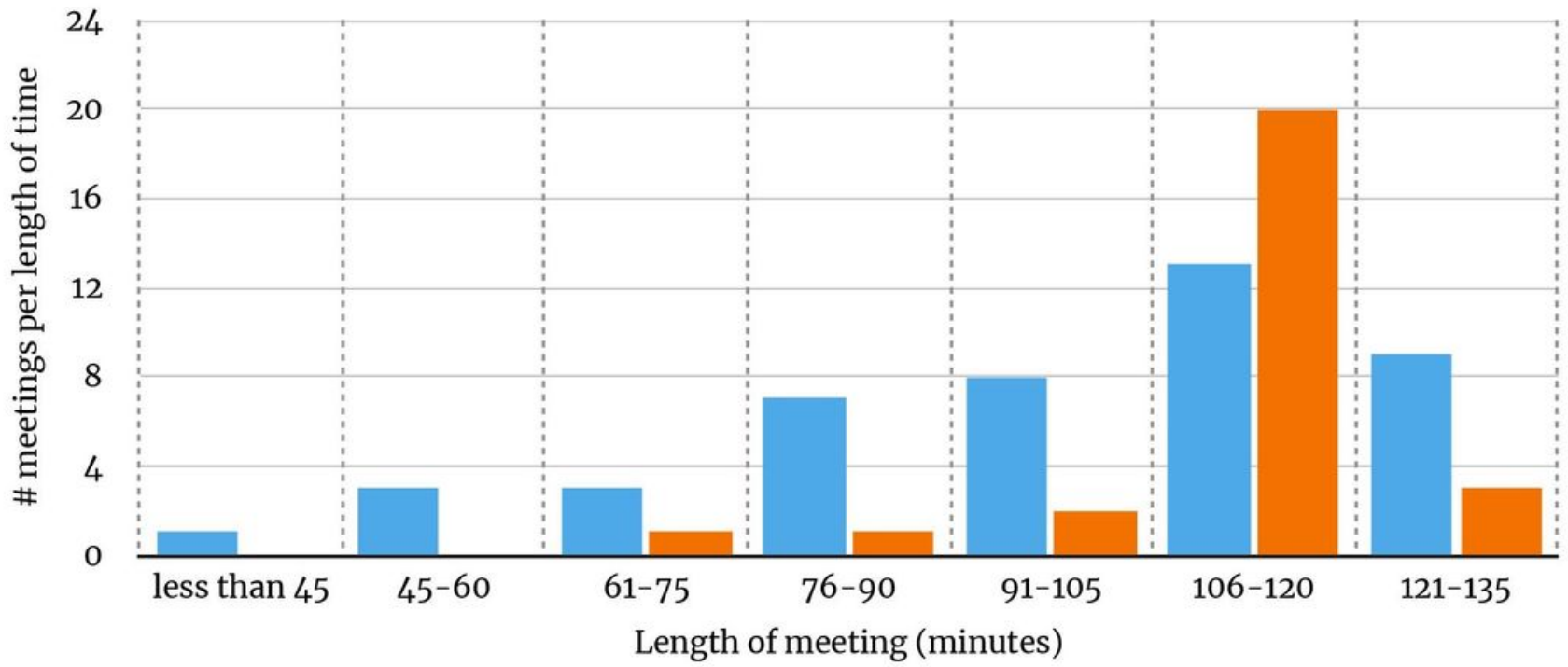

Cohort 2

LPHAs

University Facilitator

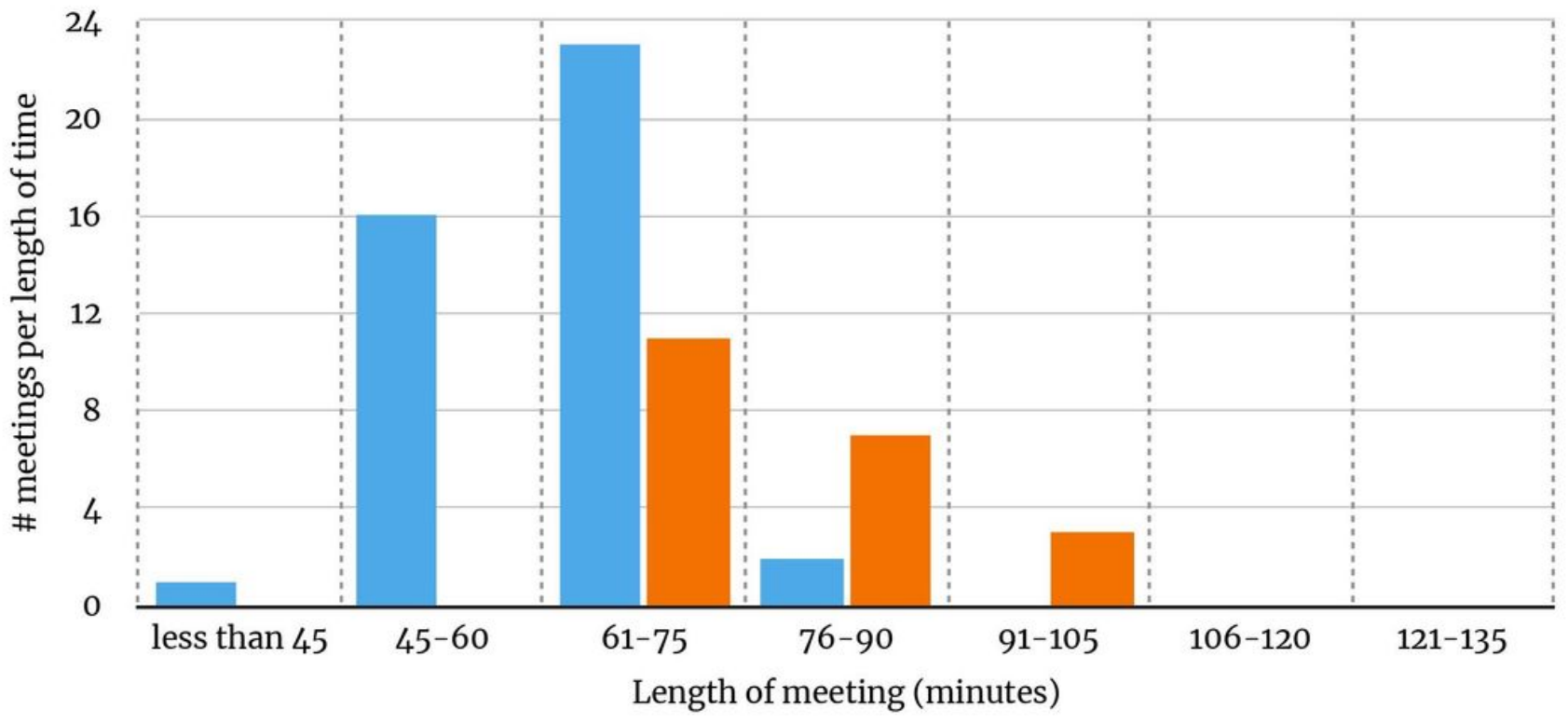

Figure 4

Length of meetings for cohorts 1 and 2 

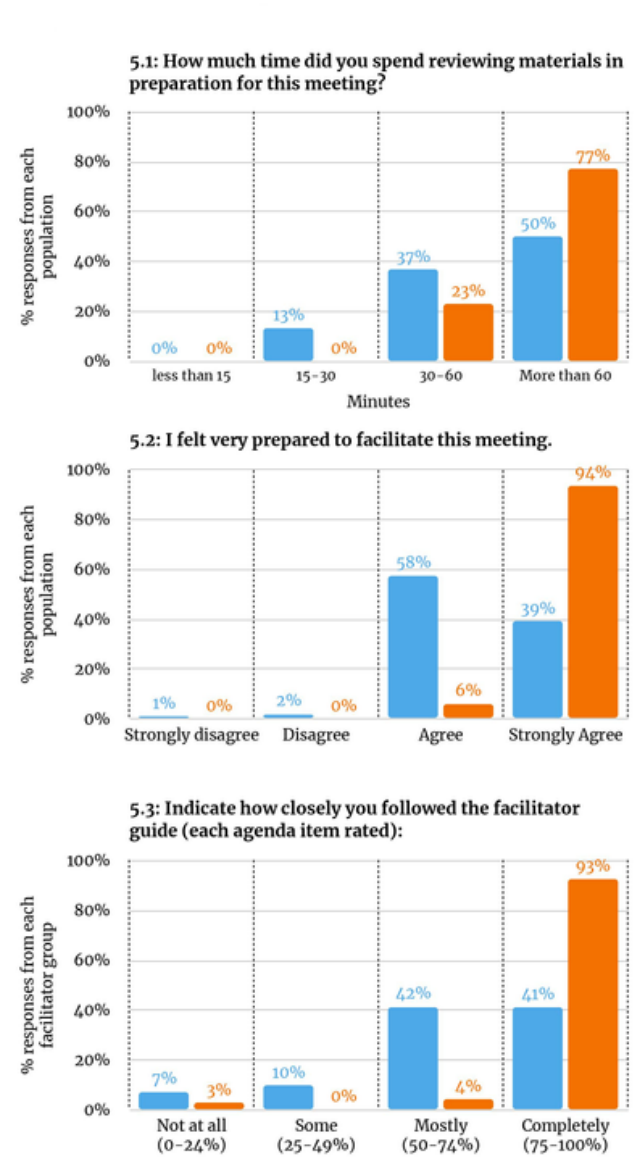

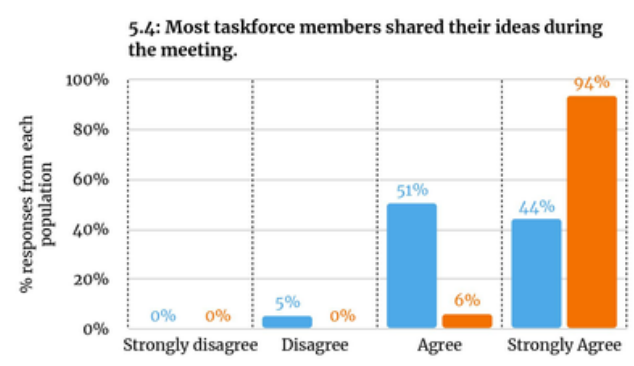

LPHAS University Facilitator

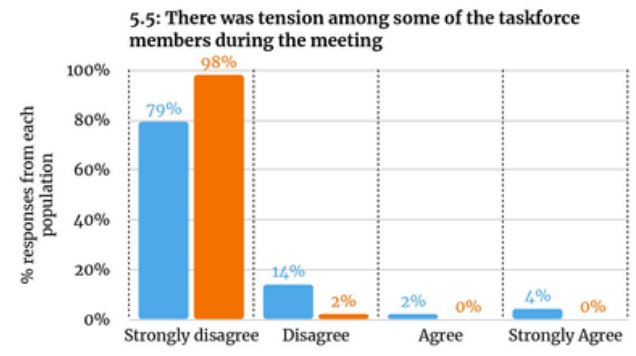

\section{Figure 5}

\section{Facilitator Ratings}




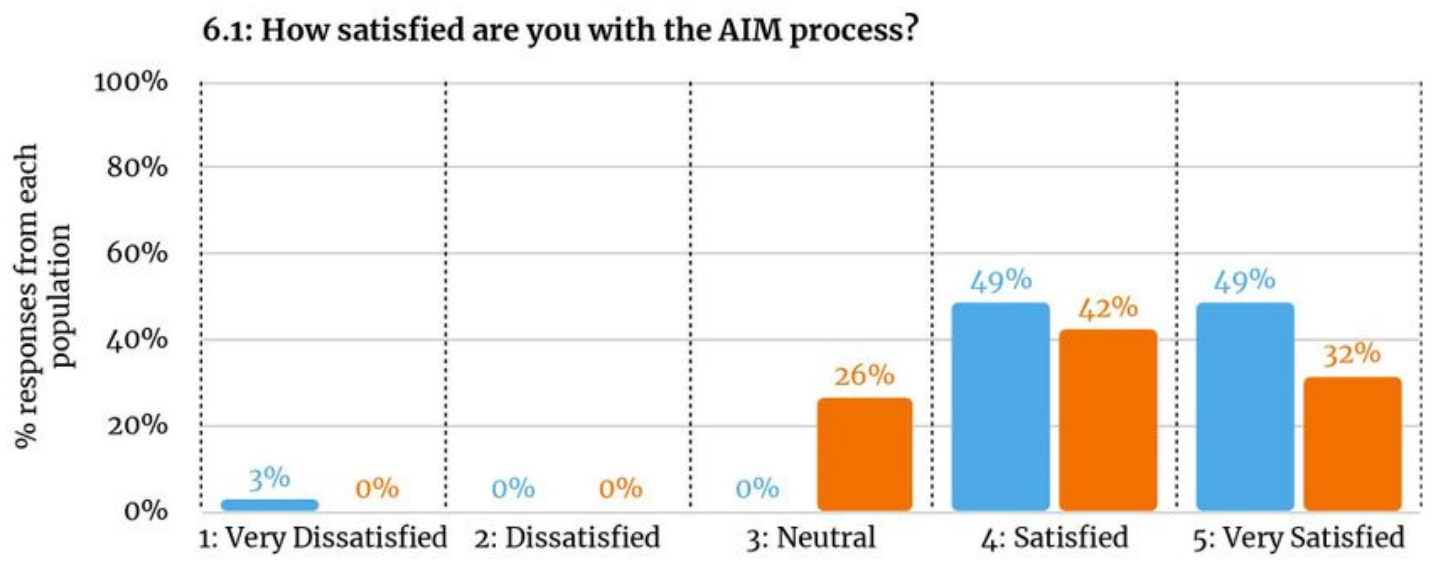

6.2: How satisfied are you with the facilitator?

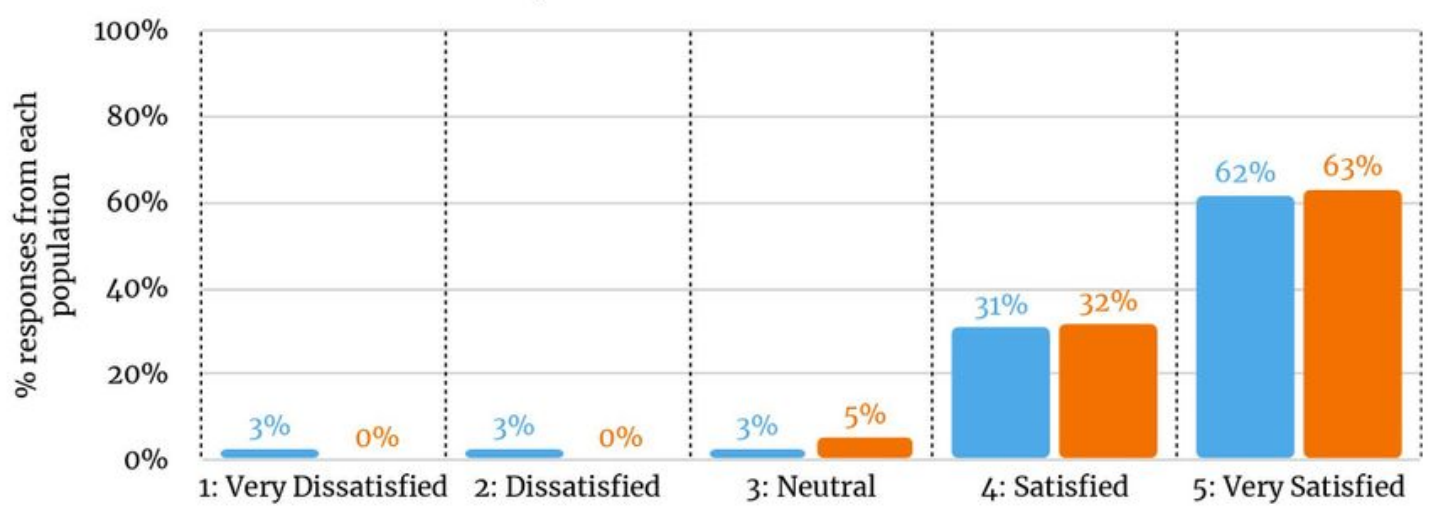

6.3: Our AIM Facilitator was from our community

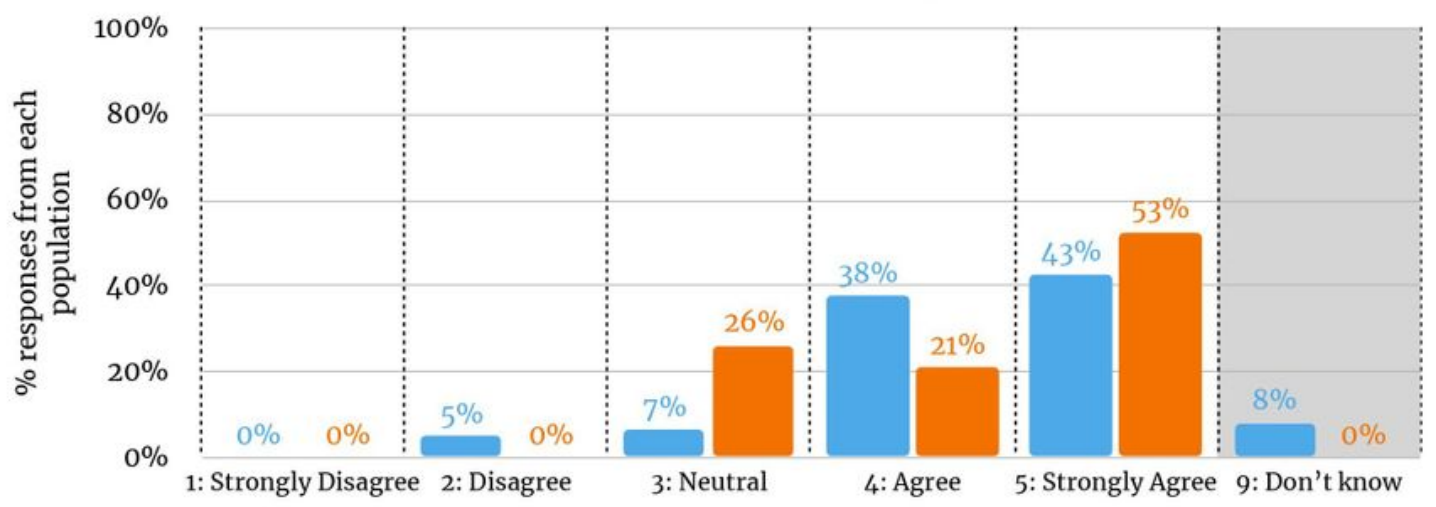

Figure 6

Taskforce member ratings

\section{Supplementary Files}

This is a list of supplementary files associated with this preprint. Click to download. 
- StaRIchecklistforauthorcompletion.docx

- Table1.jpg 